\title{
Comparison and merging of ozone profile data from various measurement techniques at NDACC Alpine station
}

\author{
Sophie Godin-Beekmann ${ }^{1 *}$, Sergey Khaykin ${ }^{1}$, Maud Pastel ${ }^{1}$ \\ Laboratoire Atmosphère, Milieux, Observations Spatiales (LATMOS), Centre de la Recherche Scientifique, \\ Université de Versailles Saint-Quentin en Yvelines \\ 11 boulevard d'Alembert, 78200 Guyancourt, France \\ (*) E-mail: sophie.godin-beekmann@latmos.ipsl.fr
}

Received / Recibido: 15/05/2015 Accepted / Aceptado: 26/08/2015

DOI: $10.7149 /$ OPA.48.3.185

\begin{abstract}
:
Within the Network for the Detection of Atmospheric Composition Changes (NDACC), various remote sensing techniques are used in addition to in situ ozone sounding measurements for the long-term evaluation of the ozone vertical distribution. These techniques, using e.g. microwave spectrometers, Fourier Transform Infrared spectrometers or laser radiation (lidars), are very different in terms of vertical distribution, time sampling and precision, which can present some difficulties for the validation of satellite data or the products of the European Monitoring atmospheric composition \& climate Service (MACC). A methodology was developed for the integration of profile ozone data from various sources in order to provide consistent ozone vertical distribution time series as well as tropospheric and stratospheric ozone partial columns. This methodology was developed for measurements performed in the stations forming the Alpine station (e.g. Haute-Provence Observatory OHP - France, Bern - Switzerland, Jungfraujoch - Switzerland). Ozone measurements from the ozone DIAL lidar instrument and ozone sondes at OHP, the microwave spectrometer at Bern and the FTIR spectrometer at the Jungfraujoch station were used for this purpose.
\end{abstract}

Key words: Ozone lidar, merging, comparison, FTIR, Microwave spectrometer

\section{REFERENCES AND LINKS / REFERENCIAS Y ENLACES}

[1] Dumitru, M. C., K. Hocke, N. Kämpfer, and Y. Calisesi, Comparison and validation studies related to ground-based microwave observations of ozone in the stratosphere and mesosphere, J. Atmos. Sol.Terr. Phy., 68, 745-756 (2006) http://dx.doi.org/10.1016/i.jastp.2005.11.001

[2] Godin-Beekmann, S., J. Porteneuve, A. Garnier, Systematic DIAL ozone measurements at Observatoire de Haute-Provence, J. Env. Monitoring, 5, 57-67 (2003) http://dx.doi.org/10.1039/b205880d

[3] Barret B., M. De Mazière and P. Demoulin, Retrieval and characterization of ozone profiles from solar infrared spectra at the Jungfraujoch, J. Geophys. Res., 107, 4788-4803 (2002). http://dx.doi.org/10.1029/2001JD001298

[4] Froidevaux, L., Livesey, N.J., Read, W. G., Jiang, Y. B., Jimenez, C., Filipiak, M. J., Schwartz, M. J., Santee, M. L., Pumphrey, H. C., Jiang, J. H., Wu, D. L., Manney, G. L., Drouin, B. J., Waters, J.W., Fetzer, E. J., Bernath, P. F., Boone, C. D. Walker, K. A., Jucks, K. W., Toon, G.C., Margitan, J.J., Sen, B., Webster, C.R., Christensen, L.E., Elkins, J.W., Atlas, E., Lueb, R. A., and Hendershot, R.,, Early validation analyses of atmospheric profiles from EOS MLS on the Aura satellite, IEEE Transactions on Geoscience and Remote Sensing, 44, No. 5, (2006). http://dx.doi.org/10.1109/TGRS.2006.864366

[5] Pommereau, J.P. and F. Goutail, 03 and NO2 Ground-Based Measurements by Visible Spectrometry during Arctic Winter and Spring 1988, Geophys. Res. Lett., 891, (1988). http://dx.doi.org/10.1029/GL015i008p00891 


\section{Introduction}

Since 1991, various instruments based on remote sensing techniques have been deployed within the Network for the Detection of Atmospheric Composition Changes (NDACC) in addition to in situ ozone sounding measurements, for the long-term evaluation of the ozone vertical distribution. Each type of instrument, e.g. microwave spectrometers, Fourier Transform Infrared spectrometers or lidars have their own specificity and advantages with respect to vertical resolution, temporal sampling or uncertainty as a function of altitude, which can present some difficulties for the validation of satellite data or the products of the European Monitoring atmospheric composition \& climate Service (MACC). Within the Demonstration Network Of ground-based Remote Sensing Observations in support of the Copernicus Atmospheric Service (NORS) European Project, we developed a methodology for integrating groundbased ozone profile data from different types of measurements, in order to provide consistent and homogeneous ozone vertical distribution time series as well as tropospheric and stratospheric ozone partial columns at the so-called NDACC alpine station that includes the stations of Haute-Provence Observatory (OHP - France), Bern (Switzerland) and Jungfraujoch (Switzerland).

\section{Methodology}

The FTIR, lidar and microwave techniques used for the measurement of ozone profiles have been described in detail, e.g. [1], [2], [3]. Measurements are based on passive or active (lidar) remote sensing techniques and are characterized by different temporal sampling, vertical resolution and error profiles. Ozone sonde measurements also used in this work are based of in situ sensing of ozone concentration by a ballon borne electrochemical sensor coupled to a Teflon air pump and interfaced to a meteorological radiosonde.

The construction of the merged ozone profile time series is based on the assumption that the bias between each measurement type at the various stations is mainly instrumental, except for the stations located in the Alpine area where geophysical bias linked to statistically different sampled air masses can also be found due to the distance between the stations.

Due to the different characteristics of the ozone profiles in terms of vertical resolution and validity domain, a compromise has to be made in order to integrate the data. For instance the vertical resolution of higher resolved measurements, e.g. from ozone sondes and lidar, has to be degraded using the averaging kernels of the passive remote sensing techniques (FTIR and microwave). Also the difference between FTIR and microwave measurements can be due to the use of different a priori profiles in the retrieval and this difference has to be corrected. After correction of these potential sources of bias, systematic differences can still persist. Satellite measurements can then be used in order to investigate the remaining biases and eventually correct them.

The various steps of the integration methodology can thus be summarized as follows:

- Evaluation of the validity domain and vertical resolution of the various data sets.

- Adjustment of vertical resolutions: smoothing of high resolved data.

- Check of bias due to a priori profile (for FTIR and microwave data) and correction.

- Check of remaining bias using satellite data and correction

- Check of geophysical bias

- Data integration

- Calculation of stratospheric and tropospheric partial columns

\section{2.a. Validity domain and vertical resolution of the data sets}

The validity domain and vertical resolution of the measurements is summarized in Table 1: 
TABLE I. Validity domain and vertical resolution of measurement techniques considered in the study

\begin{tabular}{|c||c|c|c|}
\hline & Technique & Altitude range & Resolution (km) \\
\hline \hline Lidar & $\begin{array}{c}\text { active remote } \\
\text { sensing (UV) }\end{array}$ & $10-45 \mathrm{~km}$ & $0.5-5$ \\
\hline Microwave & $\begin{array}{c}\text { passive remote } \\
\text { sensing }\end{array}$ & $20-60 \mathrm{~km}$ & $10-15$ \\
\hline FTIR & $\begin{array}{c}\text { passive remote } \\
\text { sensing (IR) }\end{array}$ & $4-42 \mathrm{~km}$ & $7-15$ \\
\hline $\begin{array}{c}\text { Ozone } \\
\text { sonde }\end{array}$ & $\begin{array}{c}\text { in situ } \\
\text { electrochemical } \\
\text { sensor }\end{array}$ & $0-35 \mathrm{~km}$ & 0.3 \\
\hline
\end{tabular}

\section{2.b.- Data smoothing}

Lidar and ozone sondes measurements are characterized by a higher vertical resolution compared to that of FTIR and microwave instrument. In order to evaluate their systematic differences with respect to microwave and FTIR measurements, the profiles have to be smoothed using the following formula:

$$
x_{s}=x_{a}+A\left(x_{h}-x_{a}\right)
$$

where $x_{s}$ is the smoothed lidar or ozone sonde profile, $x_{h}$ is the initial lidar or ozone sonde profile and $x_{a}$ is the FTIR or microwave a priori profile. The matrix A is the FTIR or microwave averaging kernel matrix.

Examples of microwave and FTIR averaging kernels are displayed in Figure 1.
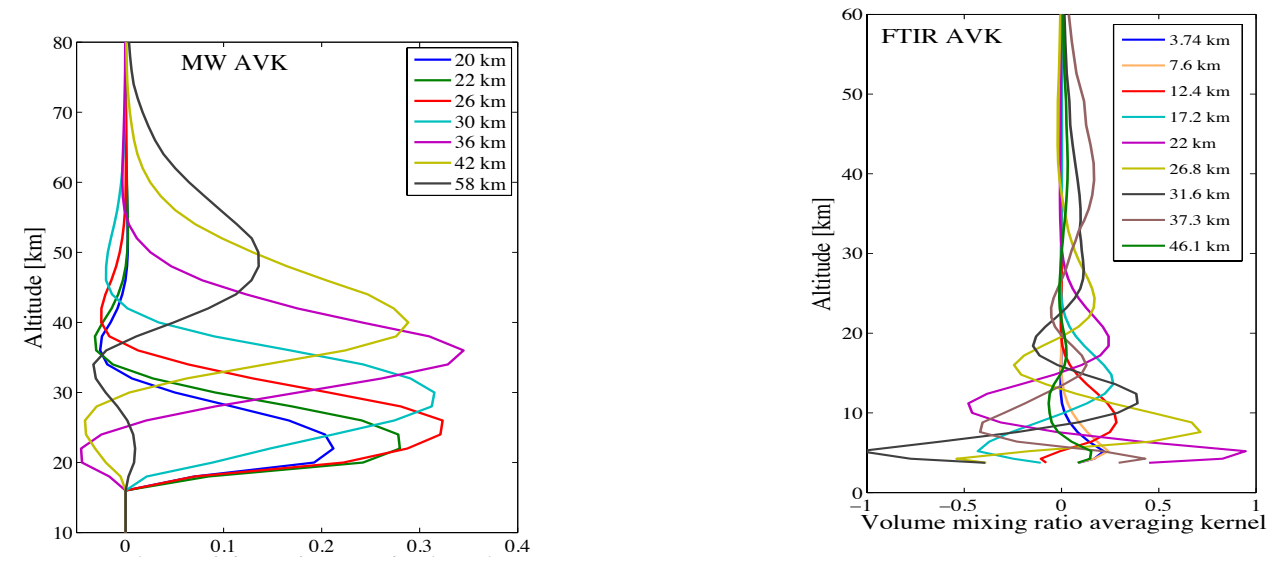

Fig.1. Averaging kernels for the microwave measurements performed in Bern (Switzerland) and FTIR measurements performed in Jungfraujoch (Switzerland)

In equation (1), $x_{h}$ must cover the same altitude range as the averaging kernels. Therefore, the lidar or ozone sonde profiles have to be extended as a function of altitude. In the case of OHP for example, an ozone sonde climatology has been used to extend the lidar data from $15 \mathrm{~km}$ to the ground and a climatology based on SAGE II satellite measurements selected in the vicinity of the station has been used for the upper range.

\section{2.c.- Instrumental bias}

In order to evaluate the validity of the various data sets, their respective systematic differences for coincident data ( $\pm 12 \mathrm{~h}$ difference) have been investigated and compared to similar systematic difference with measurements performed by the AURA-MLS satellite instrument [4]. The AURA-MLS measurements were selected within a domain of $4^{\circ}$ in longitude and $3^{\circ}$ in latitude around each station. 
In the case of microwave and FTIR measurements, a first source of systematic difference between measurements can be due to different a priori profiles. Indeed in the case of Alpine stations, Bern microwave and Jungfraujoch FTIR measurements use different a priori profiles. Bern uses monthly climatologies based on ECMWF data in the lower range (up to $20 \mathrm{hPa}$ ) and MLS data in the higher range, while Jungfraujoch uses an annual climatology based on Payerne ozone sonde data and Bern microwave data in the upper range. In order to improve the comparison, a priori profiles have to be adjusted. FTIR measurements have thus been corrected using the microwave a priori profiles.

Systematic differences between lidar and microwave data for coincident dates are also investigated. AURA-MLS data are then used in order to decide which data set is the most accurate. The respective systematic differences for coincident data ( $\pm 12 \mathrm{~h}$ difference) have been investigated and compared to similar systematic difference with measurements performed by the satellite instrument (Figure 2).

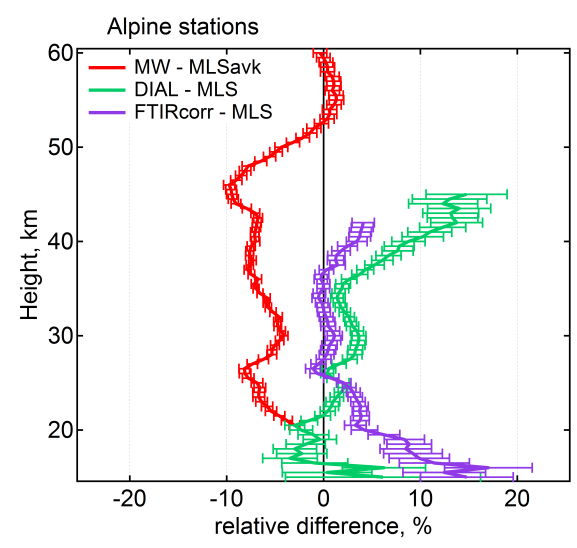

Fig. 2. Average bias between FTIR corrected for a priori and MLS coincident measurements (purple), lidar and MLS (green) and microwave and MLS (red) measurements in the case of the alpine stations.

For the comparison between lidar and MLS data, no additional smoothing was applied since both measurement types are characterized by similar vertical resolution. Lidar data have a higher resolution in the lower range (below $30 \mathrm{~km}$ ) and a lower resolution in the higher range (above $30 \mathrm{~km}$ ). The bias between lidar and ECC data at OHP is shown in Figure 3.

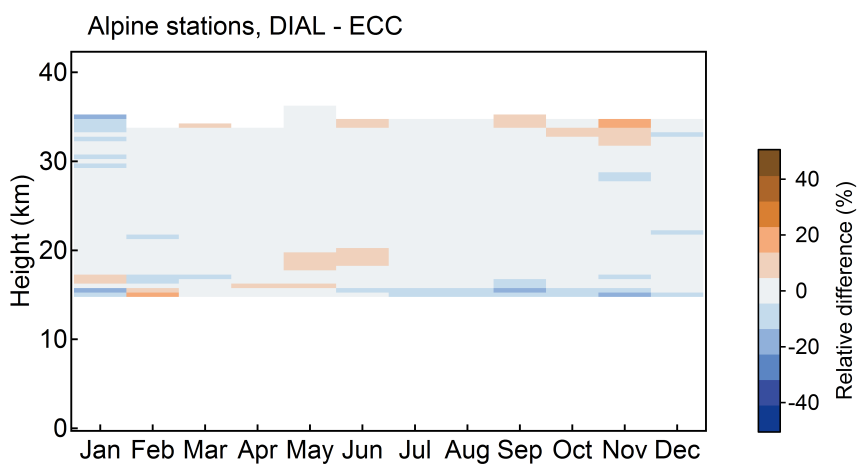

Fig.3. Climatological bias between coincident lidar and ECC ozone sonde data at OHP.

Since lidar data present a somewhat lower bias with respect to MLS data and very small bias with respect to ozone sonde data, microwave data have been corrected from their bias with MLS. Regarding Jungfraujoch FTIR data, their bias with respect to lidar and ozone sonde data at OHP and Payerne was also investigated. As mentioned previously, FTIR data have been corrected using the a priori profile of MW. The FTIR climatological systematic difference (over the 2003 - 2013 period) with respect to OHP DIAL data (smoothed with MW AVK) and Payerne ozone sondes are displayed in Figure 4. 

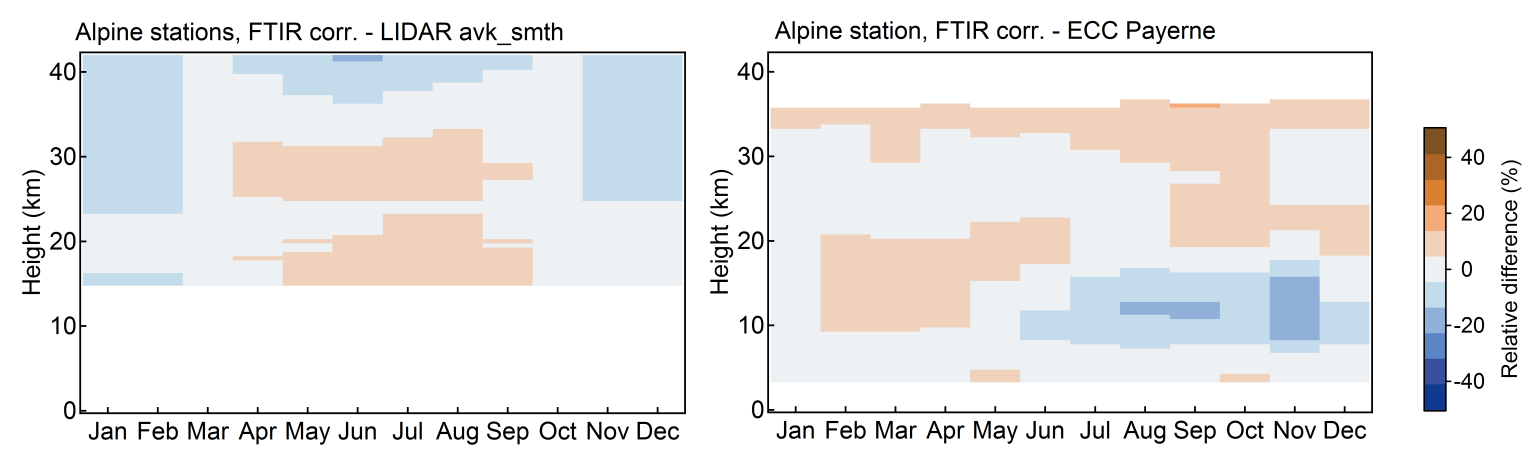

Fig. 4: Systematic difference between a priori corrected FTIR data and (left) smoothed DIAL data, (right) Payerne ozone sondes.

\section{2.d.- Geophysical bias}

Both stations located in Switzerland are located at a distance as the crow flies of $60 \mathrm{~km}$, while OHP is located at about $350-370 \mathrm{~km}$ from both other stations. Because of the distance between OHP and the other sites, possible geophysical bias has been investigated. This bias is evaluated using coincident measurements from AURA-MLS in the vicinity of the various sites (Figure 5). Results showed that the difference between MLS measurements obtained at OHP and at both other stations is generally very small above $20 \mathrm{~km}$. Below $20 \mathrm{~km}$, MLS measurements uncertainty increases rapidly, which could explain the larger biases observed.

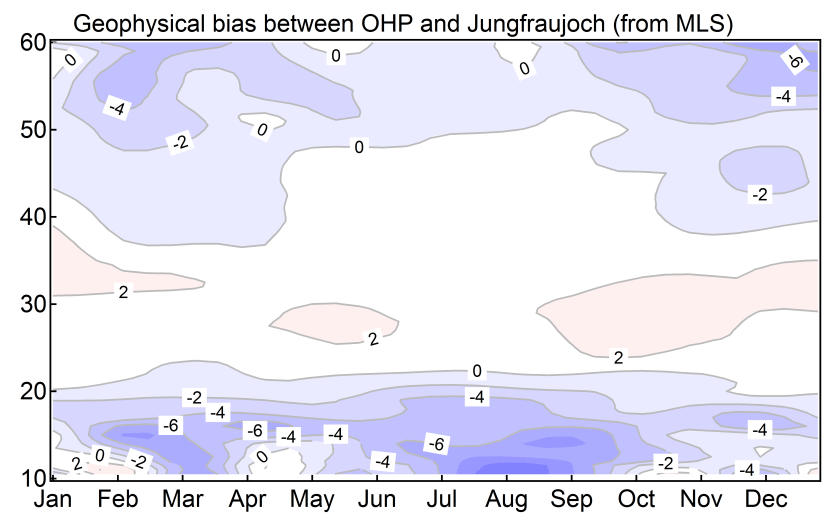

Fig.5. Difference between coincident MLS ozone measurements obtained at OHP and Jungfraujoch.

In order to better understand the measurement difference below $20 \mathrm{~km}$, the systematic difference between OHP and Payerne ozone sondes measurements on coincident days was analysed. Results of the climatological difference showed biases not exceeding $10 \%$. The small values of the obtained biases indicate that the geophysical bias between the OHP and other Alpine stations is very small and similar to the estimated error of the various measurements. As a consequence, no geophysical bias correction was applied to the individual data before the merging.

\section{Data integration}

After the corrections presented in the previous section, e.g. a priori profile correction in the case of FTIR and MLS bias correction in the case of microwave observations, the various data sets show systematic differences in the range of $\pm 10 \%$, which makes them suitable for merging.

Merged ozone profile data are computed from the error weighted average of the individual coincident daily ozone profiles corrected from eventual instrumental and geophysical bias. A general formula for the computation of merged ozone data is the following:

$$
O_{3}(z)=\sum_{i=1}^{n} w_{i}(z) B_{i}(z) G_{i}(z) O_{3 i}(z)
$$

where $O_{3}(\mathrm{z})$ is the merged ozone profile, $w_{i}(z)$ is the weight linked to the error of the measurements, $B_{i}(z)$ corresponds to the correction for eventual instrumental bias, $G_{i}(z)$ is the correction for geophysical 
bias, $O_{3 i}(\mathrm{z})$ are the invidual eventually smoothed ozone profile sources and $\mathrm{n}$ is the number of individual profiles taken into account. The weight related to the error of the measurements is computed as follows: $w_{i}(z)=\frac{\varepsilon_{i}^{-1}(z)}{\sum_{i=1}^{n} \varepsilon_{i}^{-1}(z)} \quad$ where $\varepsilon_{i}(z)$ is the error profile of the individual ozone measurements.

Figure 6, which displays the vertical distribution of average estimated error for each measurement type considered in the study case, shows how the error related weight will affect the contribution of each measurement in the merged ozone profile, as a function of altitude.

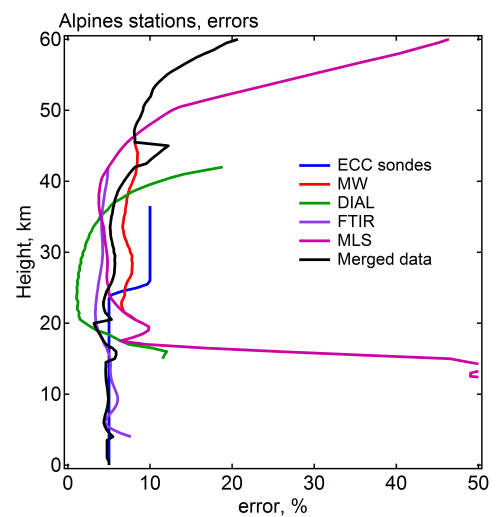

Fig. 6. Vertical distribution of average estimated error for measurements performed in the Alpine stations and for MLS measurements performed in the vicinity of these stations.

\section{Results}

As mentioned in the previous sections, the integrated data for the Alpine stations, are constructed from the error weighted average of the following individual profiles:

- Smoothed OHP lidar data using Bern microwave averaging kernels

- $\quad$ Corrected Bern MW data from their bias with MLS data

- $\quad$ Corrected Jungfraujoch FTIR data using microwave a priori profiles

- Smoothed OHP ozone sonde data using Jungfraujoch FTIR averaging kernels

- $\quad$ Smoothed Payerne ozone sonde data using Jungfraujoch FTIR averaging kernels
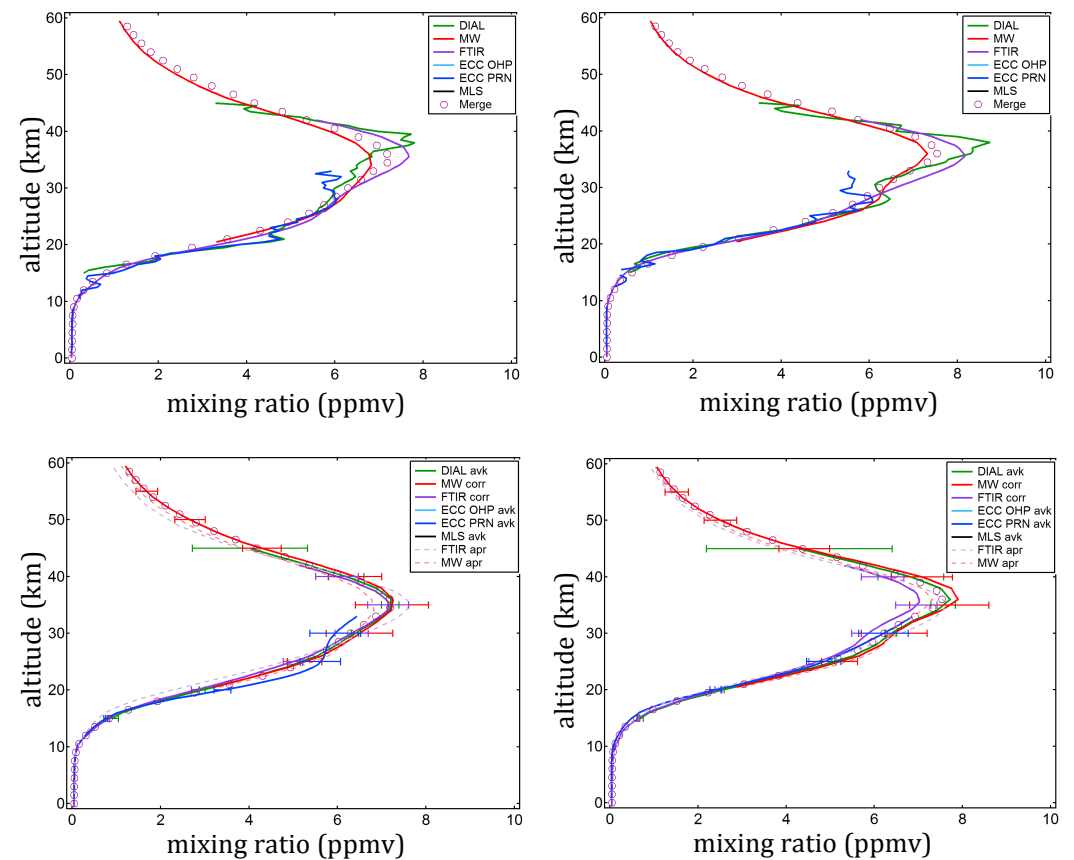

Fig. 7. Example of merged ozone profile (violet open circle) compared to the various individual profiles. 
Examples of merged ozone profile for the Alpine stations case is displayed in Figure 7. The upper panels of the Figure show individual profiles for one measurement day. Lower panels show the corrected and smoothed individual profiles used for the computation of the merged ozone profile on that day.

Once the merged ozone profiles are computed, the stratospheric and tropospheric partial columns can be computed by integrating the tropospheric and stratospheric part of the merged vertical profile after determination of the tropopause altitude. The tropopause altitude is computed using the standard WMO definition, which defines the tropopause as "the lowest level at which the lapse-rate decreases to $2^{\circ} \mathrm{C} / \mathrm{km}$ or less, provided that the average lapse-rate between this level and all higher levels within $2 \mathrm{~km}$ does not exceed $2^{\circ} \mathrm{C} / \mathrm{km}^{\prime \prime}$.

The total ozone columns, which were derived from the integration of the merged ozone profiles have been compared to the SAOZ UV-Visible [5] total ozone data at OHP (Figure 8). The comparison shows a good agreement between both data sets.

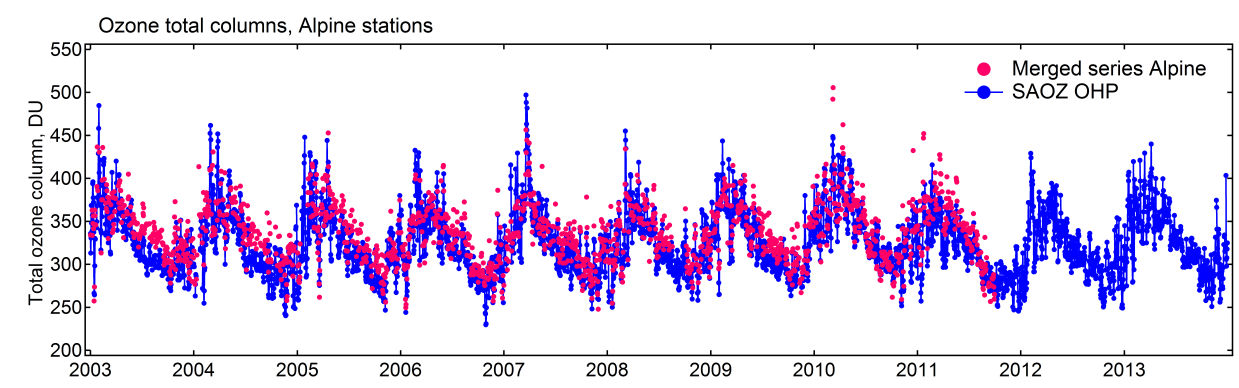

Fig. 8. Comparison of total ozone columns derived from the merged ozone data and total ozone columns observed at OHP with the SAOZ UV-Visible spectrometer.

\section{Acknowledgements}

This study was performed in the framework of the NORS FP7 European project. The authors wish to thank Klemens Hocke of University of Bern (Switzerland) for providing the Bern Microwave ozone data and Emmanuel Mahieu of University of Liège (Belgium) for the FTIR ozone data. They also wish to acknowledge the work performed by the personnel at the OHP, Bern and Jungfraujoch stations for the operation of the instruments. 